\title{
Hoyeraal-Hreidarsson syndrome caused by a germline mutation in the TEL patch of the telomere protein TPP1
}

\author{
Hande Kocak, ${ }^{1,11}$ Bari J. Ballew, ${ }^{2,11}$ Kamlesh Bisht, ${ }^{3,11}$ Rebecca Eggebeen, ${ }^{4}$ Belynda D. Hicks, ${ }^{4}$ \\ Shalabh Suman, ${ }^{4}$ Adri O'Neil, ${ }^{4}$ Neelam Giri, ${ }^{2}$ NCI DCEG Cancer Genomics Research Laboratory, ${ }^{2,9}$ \\ NCI DCEG Cancer Sequencing Working Group, ${ }^{2,10}$ Ivan Maillard, ${ }^{5,6,7}$ Blanche P. Alter, ${ }^{2}$ \\ Catherine E. Keegan, ${ }^{1,8}$ Jayakrishnan Nandakumar, ${ }^{3}$ and Sharon A. Savage ${ }^{2}$ \\ ${ }^{1}$ Department of Human Genetics, University of Michigan, Ann Arbor, Michigan 48109, USA; ${ }^{2}$ Division of Cancer Epidemiology \\ and Genetics (DCEG), National Cancer Institute (NCI), Rockville, Maryland 20850, USA; ${ }^{3}$ Department of Molecular, Cellular, \\ and Developmental Biology, University of Michigan, Ann Arbor, Michigan 48109, USA; ${ }^{4}$ Cancer Genomics Research Laboratory, \\ Leidos Biomedical Research, NCI-Frederick, Rockville, Maryland 20850, USA; ${ }^{5}$ Life Sciences Institute, University of Michigan, \\ Ann Arbor, Michigan 48109, USA; ${ }^{6}$ Division of Hematology-Oncology, Department of Internal Medicine, University of Michigan, \\ Ann Arbor, Michigan 48109, USA; ${ }^{7}$ Department of Cell and Developmental Biology, Ann Arbor, Michigan 48109, USA; \\ ${ }^{8}$ Department of Pediatrics, University of Michigan, Ann Arbor, Michigan 48109, USA
}

Germline mutations in telomere biology genes cause dyskeratosis congenita (DC), an inherited bone marrow failure and cancer predisposition syndrome. DC is a clinically heterogeneous disorder diagnosed by the triad of dysplastic nails, abnormal skin pigmentation, and oral leukoplakia; Hoyeraal-Hreidarsson syndrome (HH), a clinically severe variant of DC, also includes cerebellar hypoplasia, immunodeficiency, and intrauterine growth retardation.

Approximately $70 \%$ of DC cases are associated with a germline mutation in one of nine genes, the products of which are all involved in telomere biology. Using exome sequencing, we identified mutations in Adrenocortical Dysplasia Homolog (ACD) (encoding TPP1), a component of the telomeric shelterin complex, in one family affected by HH. The proband inherited a deletion from his father and a missense mutation from his mother, resulting in extremely short telomeres and a severe clinical phenotype. Characterization of the mutations revealed that the single-aminoacid deletion affecting the TEL patch surface of the TPP1 protein significantly compromises both telomerase recruitment and processivity, while the missense mutation in the TIN2-binding region of TPP1 is not as clearly deleterious to TPP1 function. Our results emphasize the critical roles of the TEL patch in proper stem cell function and demonstrate that TPP1 is the second shelterin component (in addition to TIN2) to be implicated in DC.

[Keywords: dyskeratosis congenita; Hoyeraal-Hreidarsson syndrome; telomere; TPP1; $A C D$; telomerase]

Supplemental material is available for this article.

Received July 4, 2014; revised version accepted August 29, 2014.

Dyskeratosis congenita (DC) is a rare cancer-prone inherited bone marrow failure syndrome caused by dysfunctional telomere maintenance (Dokal 2011; Ballew and

\footnotetext{
${ }^{9}$ The NCI DCEG Cancer Genomics Research Laboratory is Sara Bass, Joseph Boland, Laurie Burdett, Salma Chowdhury, Michael Cullen, Casey Dagnall, Herbert Higson, Amy A. Hutchinson, Kristine Jones, Sally Larson, Kerrie Lashley, Hyo Jung Lee, Wen Luo, Michael Malasky, Michelle Manning, Jason Mitchell, David Roberson, Aurelie Vogt, Mingyi Wang, Meredith Yeager, and Xijun Zhang.

${ }^{10}$ The NCI DCEG Cancer Sequencing Working Group is Neil E. Caporaso, Stephen J. Chanock, Mark H. Greene, Lynn R. Goldin, Alisa M. Goldstein, Allan Hildesheim, Nan Hu, Maria Teresa Landi, Jennifer Loud, Phuong L. Mai, Mary L. McMaster, Lisa Mirabello, Lindsay Morton, Dilys Parry, Anand Pathak, Melissa Rotunno, Douglas R. Stewart, Phil Taylor, Geoffrey S. Tobias, Margaret A. Tucker, Jeannette Wong, Xiaohong R. Yang, and Guoqin Yu.

${ }^{11}$ These authors contributed equally to this work.

Corresponding authors: savagesh@mail.nih.gov, jknanda@umich.edu

Article published online ahead of print. Article and publication date are online at http://www.genesdev.org/cgi/doi/10.1101/gad.248567.114.
}

Savage 2013). It is diagnosed clinically by the presence of the classic triad of nail dysplasia, lacy skin pigmentation, and oral leukoplakia. Substantial clinical heterogeneity exists among DC patients, even within affected families: Patients may also have pulmonary fibrosis; liver disease, esophageal, urethral, or lacrimal duct stenosis; developmental delay; dental and ophthalmologic abnormalities; and/or other complications (Ballew and Savage 2013). Patients with DC are at a very high risk of bone marrow failure and cancer, particularly myelodysplastic syndrome, acute myelogenous leukemia, and solid tu-

(C) 2014 Kocak et al. This article is distributed exclusively by Cold Spring Harbor Laboratory Press for the first six months after the full-issue publication date (see http://genesdev.cshlp.org/site/misc/terms.xhtml). After six months, it is available under a Creative Commons License (Attribution-NonCommercial 4.0 International), as described at http:// creativecommons.org/licenses/by-nc/4.0/. 
mors (usually squamous cell carcinoma of the head/neck, skin, or anogenital region) (Alter et al. 2010). DC is characterized on a molecular level by blood leukocyte telomere lengths less than the first percentile for age (Alter et al. 2012), the result of germline mutations in telomere biology genes.

Multiple modes of inheritance are associated with DC (Walne et al. 2007, 2013a,b; Vulliamy et al. 2008; Keller et al. 2012; Nelson and Bertuch 2012; Ballew et al. 2013; Le Guen et al. 2013). X-linked recessive (XLR) DC is caused by DKC1 (MIM 300126) mutations. Autosomal dominant (AD) DC can be caused by mutations in TERC (MIM 602322; encodes the telomerase RNA template TR), TERT (MIM 187270; encodes the telomerase reverse transcriptase), RTEL1 (MIM 608833), or TINF2 (MIM 604319). Autosomal recessive (AR) inheritance of mutations in TERT, RTEL1, CTC1 (MIM 613129), NOP10 (MIM 606471), NHP2 (MIM 606470), or WRAP53 (MIM 612661) also cause DC. Germline mutations in these genes account for $\sim 70 \%$ of DC cases.

Hoyeraal-Hreidarsson $(\mathrm{HH})$ syndrome is a clinically severe variant of DC marked by immunodeficiency (Jyonouchi et al. 2011), intrauterine growth retardation (IUGR), developmental delay, and cerebellar hypoplasia; the latter is characteristic of $\mathrm{HH}$ (Savage and Bertuch 2010). HH patients have extremely short telomeres, even in comparison with other DC patients (Alter et al. 2012). Mutations in a subset of DC-associated genes (DKC1 [XLR], TINF2 [AD], TERT [AR], and RTEL1 [AD and AR]) have been shown to cause $\mathrm{HH}$.

TPP1, a protein encoded by the Adrenocortical Dysplasia Homolog (ACD) gene (MIM 609377), is one of the core components of the telomeric shelterin complex (Fig. 1A). TPP1 performs multiple functions at the telomere, mediated by distinct protein domains (Fig. 1B). The central domain of TPP1 facilitates formation of a heterodimer with POT1 (MIM 606478); this complex binds and protects the single-stranded tail found at all chromosome ends (Houghtaling et al. 2004; Lei et al. 2004; Liu et al. 2004; Ye et al. 2004). Via the C-terminal domain, TPP1 binds TIN2, forming a bridge between POT1 and the dsDNAbinding TRF1/TRF2 (MIM 600951/602027) components of shelterin (Takai et al. 2011). By physically linking two critical shelterin components, TPP1 plays a central role in protecting chromosome ends (Palm and de Lange 2008).

In addition to its critical role in end protection, TPP1 is also responsible for recruiting telomerase to chromosome ends, thereby facilitating telomere extension (Fig. 1A). A group of surface-exposed amino acids in the N-terminal OB domain of TPP1 (TPP1-OB), collectively termed the TEL patch, mediates the interaction of TPP1 with telomerase, facilitates telomerase recruitment to telomeres, and stimulates telomerase enzymatic processivity (Fig. 1B; Wang et al. 2007; Xin et al. 2007; Abreu et al. 2010; Latrick and Cech 2010; Nandakumar et al. 2012; Sexton et al. 2012; Zhong et al. 2012). An intact TEL patch is required for both telomere lengthening and HeLa cell proliferation (Nandakumar et al. 2012; Nakashima et al. 2013). Because TPP1 depends on binding to TIN2 for its own recruitment to telomeres, the TPP1-TIN2 interac-
A

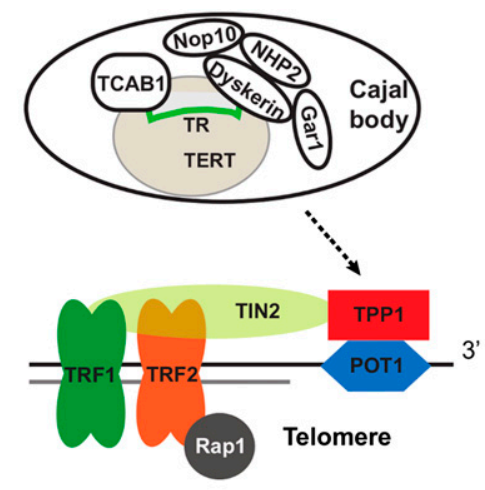

$B_{1}$

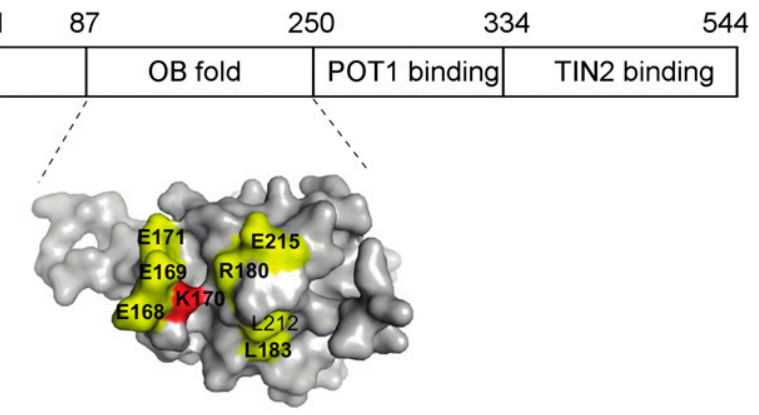

C
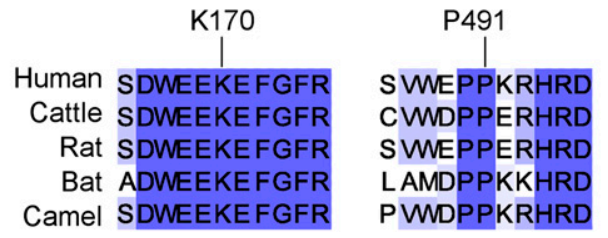

Figure 1. The affected TPP1 amino acids are in highly conserved regions. (A) This schematic diagram shows recruitment of human telomerase from Cajal bodies to telomeres coated with the six-protein shelterin complex. $(B)$ The domains of TPP1 are represented by a schematic diagram. The OB-fold domain, POT1-binding domain, and TIN2-interacting domain are shown; the structure of the OB domain is shown in surface representation, with the TEL patch amino acids in yellow and K170 in red. $(C)$ Evolutionary conservation of the affected TPP1 amino acids in mammals. Higher percent identity is indicated by a deeper purple color.

tion described above is also important for telomerase recruitment (Xin et al. 2007; Abreu et al. 2010; Zhong et al. 2012).

Here, we report the identification of a single-amino-acid deletion in the TEL patch of TPP1 and a missense mutation in the TIN2-binding domain of TPP1 in an HH proband who is negative for mutations in other DC-associated genes. Characterization of these mutants revealed that the deletion in the TEL patch severely compromises both telomerase recruitment and processivity, whereas the missense mutation has less severe effects.

\section{Results}

\section{Clinical characterization}

The male proband NCI-275-1 is an identical twin born at 29-wk gestation with IUGR. Clinical features consistent 
with $\mathrm{HH}$ were noted during the first year of life and included microcephaly, cerebellar hypoplasia, developmental delay, oral leukoplakia, nail dystrophy, and esophageal stenosis (Table 1). By age $20 \mathrm{mo}$, the proband required regular platelet and red blood cell transfusions for bone marrow failure. Fanconi anemia and ShwachmanDiamond syndrome were excluded based on a normal chromosomal breakage test and the absence of mutations in $S B D S$, respectively. Despite extremely short blood leukocyte telomere length, as demonstrated by flow cytometry with fluorescent in situ hybridization (FISH) (Fig. 2A) and by FISH/confocal microscopy of EBV-transformed lymphoblasts (Fig. 2B), sequencing did not identify mutations in any of the nine known DC-associated genes. The proband underwent successful matched unrelated hematopoietic stem cell transplantation at $3 \mathrm{yr}$ of age.

The proband's identical twin, NCI-275-2, was also affected by IUGR and died at 4 mo from complications of pertussis. The proband's older sister, NCI-275-3, is healthy and has no clinical features of DC but has very short telomeres (Fig. 2A). The proband has two healthy younger sisters who are identical twins, NCI-275-4 and NCI-275-5, with telomeres at the first percentile (Fig. 2A, B). Although the twins' telomeres are at the low end of the normal range, they do not meet the stringent criteria for a DC diagnosis (three out of four leukocyte subsets, excluding granuloctyes, below the first percentile) (Alter et al. 2012). Both parents (father, NCI-275-6, and mother, NCI-275-7) are healthy, although the father has very short telomeres, premature gray hair, and minor dental abnormalities (Fig. 2A; Table 1).

\section{Sequence analysis}

DNA from the proband (NCI-275-1), his older sister (NCI275-3), and both parents (NCI-275-6 and NCI-275-7) (Fig. $2 \mathrm{C})$ was analyzed by whole-exome sequencing, resulting in $\sim 300,000$ reported variants. We used a custom filtering algorithm to identify likely causal variants. Based on data from the National Institutes of Health Heart, Lung, and Blood Institute (NHLBI) Exome Sequencing Project (ESP), the 1000 Genomes Project, and an in-house database of 1400 exomes, we identified the rarest variants in accordance with the low prevalence of DC (Supplemental Table S2). We further filtered variants by family structure using telomere length as the phenotype of interest to minimize the effect of variable expressivity: Because the proband (NCI-275-1), older sister (NCI-275-3), and father (NCI-275-6) all have short telomeres, we hypothesized that they must share a contributing variant despite the fact that they are not equally affected clinically. This resulted in a list of 40 variants (Supplemental Table S3), only one of which was in a telomere biology gene: $A C D$ $(A C D)$, chr16:67693689-67693691delCTT (genomic coordinates correspond to GRCh37/hg19). A second ACD variant, chr16:67691750G $>$ T, shared by the proband (NCI-275-1) and mother (NCI-275-7), was also present. The presence or absence of each of the two variants was validated in all six family members by both ion semiconductor sequencing of the entire gene locus and Sanger sequencing of the region around the mutations; the healthy twins (NCI275-4 and NCI-275-5) carry neither mutation. The healthy paternal grandmother is also wild type at both of these loci; DNA was not available on any other family members.

The 3-base-pair (3-bp) deletion results in an in-frame deletion of a single amino acid, K170 (based on NM_001082486.1/NP_001075955.1). This residue is located in the OB fold of TPP1 (Fig. 1B; Wang et al. 2007). The deletion affects a conserved solvent-accessible charged loop, a likely site of molecular interaction. This is supported by reports describing the TEL patch of TPP1 (Fig. 1B), a cluster of residues encompassing this deletion that mediates interactions required for telomerase recruitment and telomerase processivity (Nandakumar et al. 2012; Zhong et al. 2012). K170 is implicated in the interaction between TPP1 and telomerase (Zhong et al. 2012), and mutation of adjacent amino acids (E169 and E171) has been shown to severely impede both telomerase recruitment and processivity (Nandakumar et al. 2012). Deletion of K170, a residue that is strictly conserved in mammals (Fig. 1C), is predicted to be deleterious by in silico algorithms (Table 2). This mutation is not reported in National Center for Biotechnology Information Single Nucleotide database build 137 (dbSNP 137), the ESP database, or the 1000 Genomes Project and is not present in our internal non-DC population.

The missense variant chr16:67691750 G>T results in the replacement of a proline by a threonine at amino acid position 491 (P491T; NM_001082486.1/NP_001075955.1). The P491T mutation resides in the C-terminal TIN2interacting domain of TPP1 (Fig. 1B); this interaction is required for TPP1 localization (and hence telomerase recruitment) to telomeres (Yang et al. 2011). P491 is also well conserved in mammals (Fig. 1C), and four of six in silico prediction algorithms list this mutation as deleterious (Table 2). This variant is listed in dbSNP as rs201441120 and is present in the ESP database $(n=6496$ individuals) with a MAF of 0.0002; however, it is not present in the 1000 Genomes Project or our internal nonDC population (total $n \approx 9900$ individuals).

\section{Telomerase recruitment}

To test the effect of deletion of K170 on telomerase recruitment, we conducted an immunofluorescence/ FISH (IF/FISH)-based telomerase recruitment assay. HeLa cells transiently transfected with plasmids encoding TERT (the catalytic subunit of telomerase), TR (the RNA subunit of telomerase), and Flag-tagged TPP1 (wild type, K1704, or P491T) were fixed and stained/probed for Flag, $\mathrm{TR}$, and coilin (a marker of Cajal bodies). Flag-tagged TPP1, TPP1-K170 , and TPP1-P491T were visualized as punctate foci (Fig. 3A). As in previous studies (Nandakumar et al. 2012), the Flag foci observed here represent telomeres insofar as they colocalize with the shelterin component RAP1 (Supplemental Fig. S1). FISH probes for TR indicated the localization of telomerase in the same nuclei. As expected, we observed that a large 


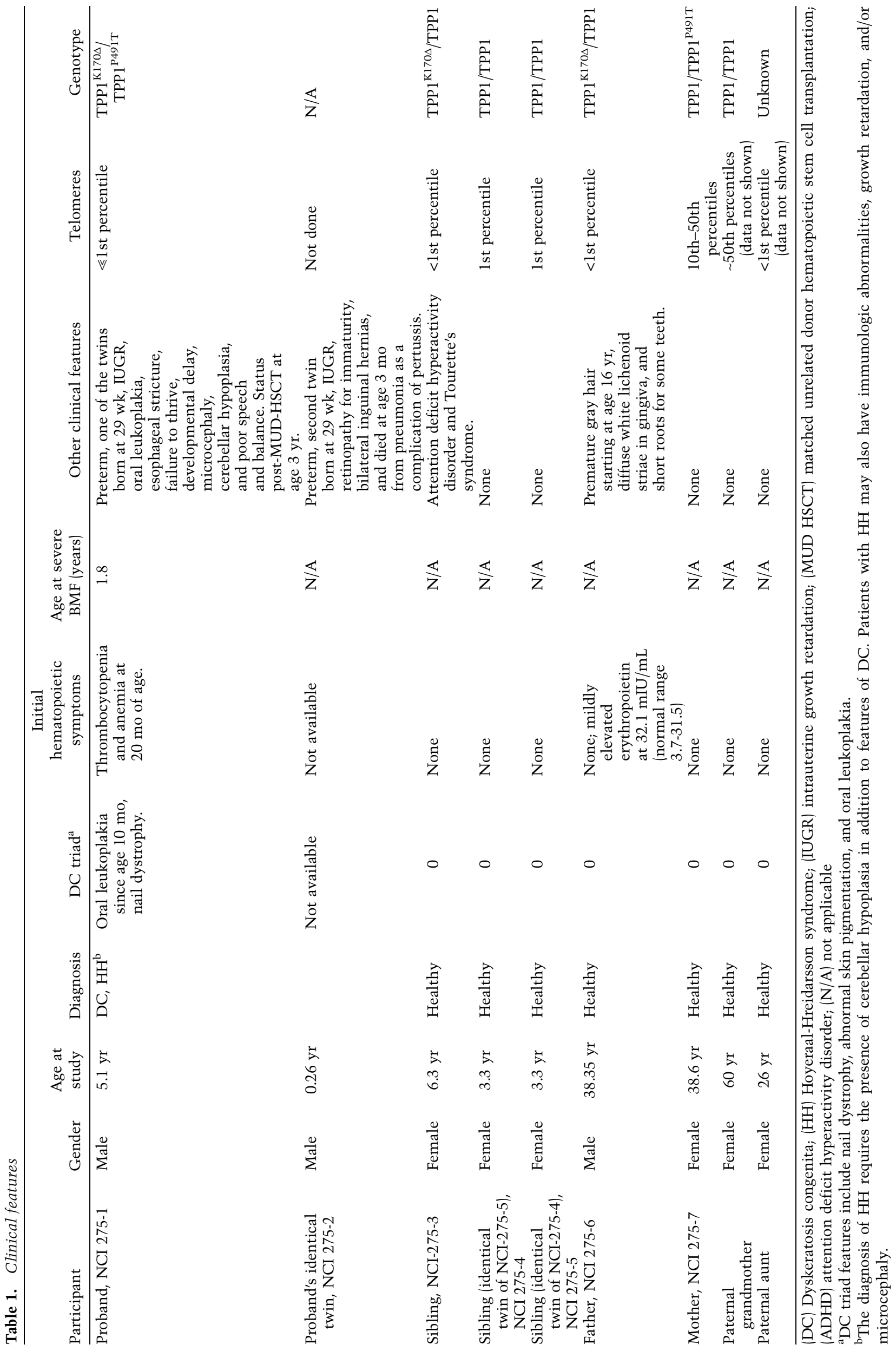




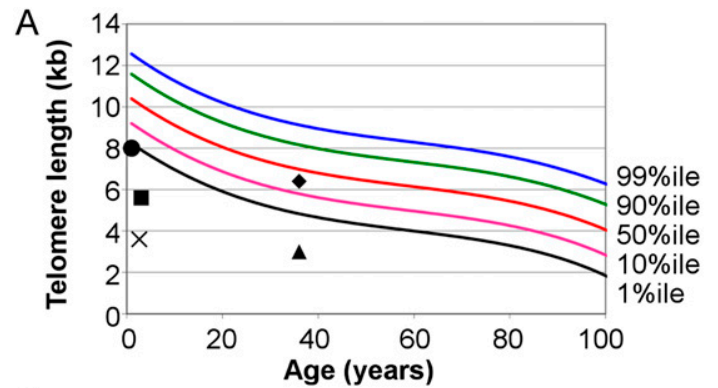

B
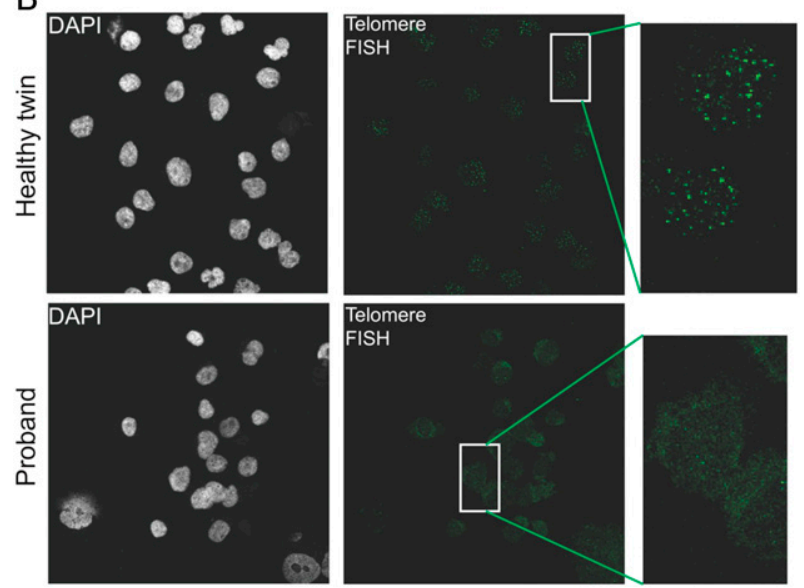

C

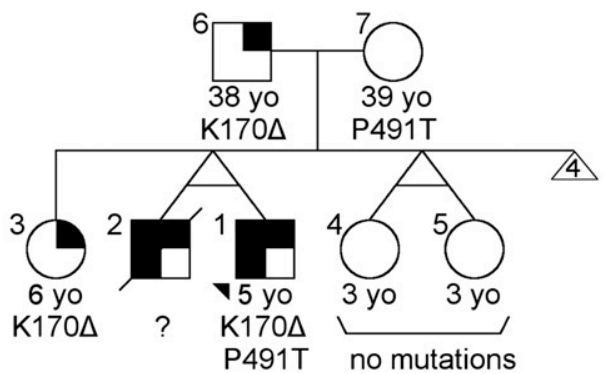

Figure 2. Lymphocyte telomere lengths and pedigree for a family affected by $\mathrm{HH}$ syndrome. (A) Lymphocyte telomere lengths for members of family NCI-275-proband (X, \#1 on the pedigree in $C$ ), healthy older sister (square, \#3), healthy twin sisters (circle, \#4 and \#5), mother (diamond, \#7), and father (triangle, \#6) -were measured by flow cytometry with FISH. (B) Telomere FISH of EBV-transformed lymphoblasts derived from proband and his healthy twin sister. $(C)$ The pedigree for NCI-275 shows the proband's first-degree relatives (proband is indicated by an arrowhead). A diagnosis of $\mathrm{HH}$ is indicated by a filled left half, and telomeres below the first percentile are indicated with a filled top right quadrant. ACD genotypes are shown below each symbol.

fraction of the TR foci localized to telomeres in the presence of wild-type TPP1 (Fig. 3A). Quantification of data collected from triplicate experiments for each TPP1 construct revealed that $54 \%$ of all telomeric foci in wildtype cells contain TR foci (Fig. 3B), confirming efficient recruitment of telomerase to telomeres by wild-type TPP1. In addition, we observed coilin (Fig. 3A) colocalizing with both telomerase and telomeres in structures referred to as neo-Cajal bodies, consistent with previous observations (Zhong et al. 2012).
In sharp contrast to cells expressing wild-type TPP1 but akin to TEL patch mutant cells (Nandakumar et al. 2012), the TR foci in cells expressing TPP1-K170 $\Delta$ rarely localize at telomeres; only $3 \%$ of Flag-TPP1-K170 $\Delta$ foci colocalize with TR foci (Fig. 3A). TR foci in TPP1-K170 cells maintained their colocalization with coilin, suggesting that the K170 $\Delta$ mutation interferes with recruitment of telomerase from Cajal bodies to telomeres.

Next, we measured telomerase recruitment in HeLa cells transiently expressing TPP1-P491T, the maternally inherited heterozygous mutation in the proband. TR efficiently colocalized with telomeres in the presence of TPP1-P491T (Fig. 3A). Quantification revealed that $65 \%$ of all telomeric foci in TPP1-P491T-expressing cells contain TR foci (Fig. 3B), suggesting that the P491T mutation does not severely interfere with the interaction of telomerase and Flag-tagged TPP1-P491T at telomeres.

\section{Telomerase processivity}

The TEL patch of TPP1 has also been shown to stimulate telomerase processivity (Nandakumar et al. 2012), enabling telomerase to synthesize long DNA products containing multiple telomeric repeats. To test the effect of TPP1-K170 1 on telomerase processivity, direct telomerase primer extension assays were performed using two methods. The first method involves using lysates of HeLa cells expressing Flag-TERT, TR, Flag-POT1, and Flag-TPP1 (wild type or mutant) as reported previously (Nandakumar et al. 2012). Although the use of HeLa extracts provides limiting amounts of Flag-POT1 and Flag-TPP1 for the telomerase activity assay, the proteins are coexpressed with telomerase in human cells, more closely recapitulating what occurs in vivo. Compared with the untransfected control, transfection of wild-type TPP1 resulted in an increase in processivity (Wang et al. 2007), indicated by the appearance of higher-molecularweight (slower-migrating) products (Fig. 4A). However, the deletion of K170 led to the disappearance of the slowest-migrating bands observed with wild-type TPP1 (Fig. 4A). Quantification of the data from multiple experiments further indicates a telomerase processivity defect in the presence of TPP1-K170 (Fig. 4C). The deleterious effect of TPP1-K170 $\Delta$ was not a result of varying protein levels, as Flag-TERT, Flag-POT1, and Flag-TPP1 protein levels were comparable in all cell lines tested (Fig. 4D). The P491T mutation does not cause a significant defect in telomerase processivity (Supplemental Fig. S2), consistent with the nonessential nature of the TIN2-binding domain for stimulation of telomerase processivity (Wang et al. 2007).

We repeated the analysis of telomerase processivity using purified, recombinant POT1 and TPP1-N (a TPP1 construct that binds POT1 as well as telomerase) (Wang et al. 2007). These proteins were added at high concentrations (see the Materials and Methods) to lysates from HEK293T cells transiently overexpressing telomerase (supertelomerase); the increased POT1/TPP1 concentrations allow for a larger stimulation of telomerase processivity (Latrick and Cech 2010). Using this approach, we saw the 
Table 2: Description of mutations and in silico analyses

\begin{tabular}{|c|c|c|}
\hline Genomic location (hg19) & chr16: 67693691 CTT $\Delta$ & chr16: $67691750 \mathrm{G}>\mathrm{T}$ \\
\hline Codon change & AAG $/-$ & CCA/aCA \\
\hline $\begin{array}{l}\text { Transcript change } \\
\text { (NM_001082486.1) }\end{array}$ & c.508_510delAAG & c. $1471 \mathrm{C}>\mathrm{A}$ \\
\hline $\begin{array}{l}\text { Protein change } \\
\text { (NP_001075955.1) }\end{array}$ & p.K170 $\Delta$ & p.P491T \\
\hline \multicolumn{3}{|l|}{ In silico predictions } \\
\hline $\begin{array}{l}\text { Polyphen-2 } \\
\quad \text { (HumDiv/HumVar) }\end{array}$ & N/A & $\begin{array}{l}\text { Probably damaging/probably } \\
\text { damaging }\end{array}$ \\
\hline SIFT & $\mathrm{N} / \mathrm{A}$ & Damaging \\
\hline PROVEAN & Deleterious & Deleterious \\
\hline Mutation taster & Disease causing & Disease causing \\
\hline Mutation assessor & N/A & Low functional impact \\
\hline FATHMM & $\mathrm{N} / \mathrm{A}$ & Tolerated \\
\hline CADD & $\begin{array}{l}\text { Among the } 10 \% \text { most } \\
\text { deleterious mutations (14.89) }\end{array}$ & $\begin{array}{l}\text { Among the } 10 \% \text { most } \\
\text { deleterious mutations }(18.96)\end{array}$ \\
\hline
\end{tabular}

characteristic threefold to fourfold increase in telomerase processivity in the presence of the POT1-TPP1 complex containing wild-type TPP1-N but not with POT1-TPP1$\mathrm{N}(\mathrm{K} 170 \Delta)$ (Fig. 4B,E). Because both TPP1-N (wild type) and TPP1-N (K170 4 ) proteins were purified to similar levels (Fig. 4F) and were added to the assay at the same concentrations, we conclude that the TPP1-K170 mutation reduces the ability of POT-TPP1 to stimulate telomerase processivity.

\section{TPP1-TIN2 interaction}

Because the P491T mutation resides in the TIN2-interacting domain of TPP1, this mutation may affect TIN2TPP1 binding. To assess the interaction between TIN2 and mutant TPP1, we performed coimmunoprecipitation (co-IP) assays (Fig. 5A,B). Whereas wild-type TPP1 and TPP1-K170 $\Delta$ efficiently precipitated with TIN2, TPP1P491T showed a modest (approximately twofold) reduction in TIN2 association.

Disruption of the TIN2-TPP1 interaction can indirectly cause a reduction in telomerase recruitment to telomeres; however, we did not see evidence of this in the telomerase recruitment assay (Fig. 3). To monitor the effect of the P491T mutation with regard to TPP1 recruitment to telomeres, we conducted telomere chromatin immunoprecipitation (ChIP) experiments. Our results show that TPP1 (as well as TRF2, a positive control) binding to telomeres is unaffected by the P491T mutation, at least under the conditions of this assay (Fig. 5C,D).

\section{TPP1 structural modeling}

To gain insight into the structural implications of this deletion, we constructed a model for TPP1-OB lacking K170 based on the TPP1-OB wild-type crystal structure (Protein Data Bank [PDB]: 2I46) using homology modeling and energy minimization (see the Materials and Methods for details). The crystal structure for the wild-type protein (Fig. 6A; Wang et al. 2007) reveals that while E168, E169, and E171 amino acid side chains are surface-exposed and available for binding telomerase, K170 is buried and directed toward the core of the wild-type protein. Strikingly, deletion of K170 results in a structural model in which

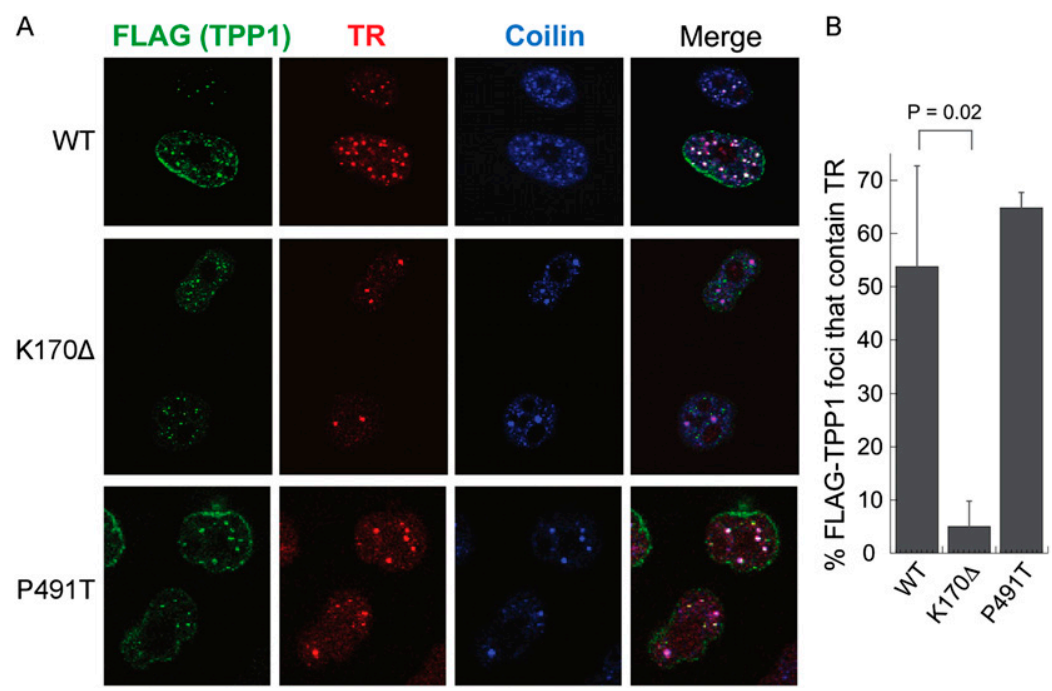

Figure 3. TPP1-K170 $\triangle$ fails to recruit telomerase to telomeres. (A) Data are shown for FISH to detect TR (red) and for IF to detect the indicated Flag-TPP1 proteins (green) and coilin (Cajal body marker; blue) for the indicated transfections. (Merge) White (green + blue + red) spots indicate recruitment of telomerase to telomeres at foci referred to as neo-Cajal bodies. Purple (blue + red) spots indicate telomerase not recruited to telomeres but rather residing in Cajal bodies. $(B)$ Quantification of telomerase recruitment data of which $A$ is representative. The average percentages of Flag-TPP1 foci that contain TR and standard deviations (error bars) were plotted for the indicated transfections. Two-tailed Student $t$-test with respect to wild type (WT) was used to calculate the $P$-value for K170A. 
A

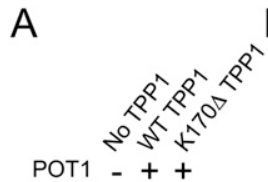

B

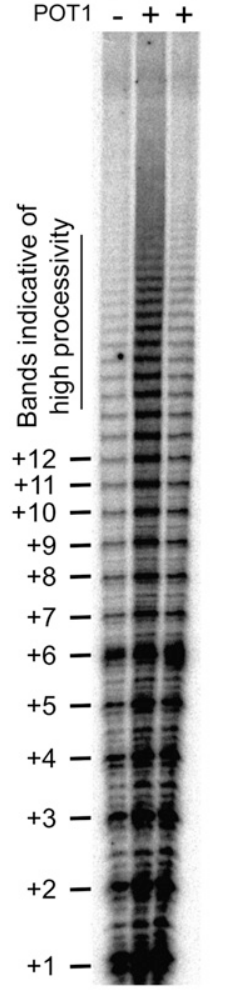

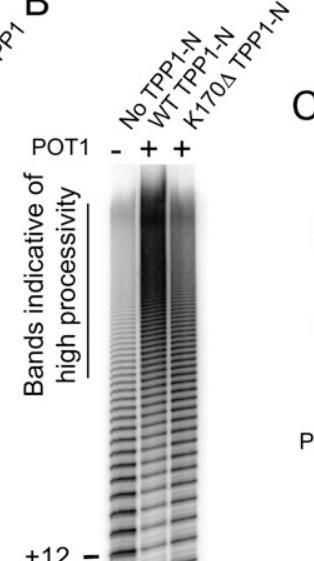

C

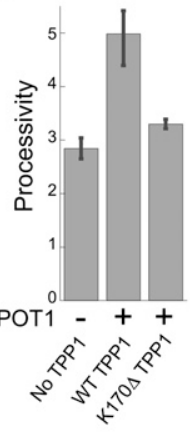

D

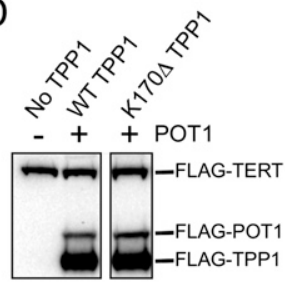

E
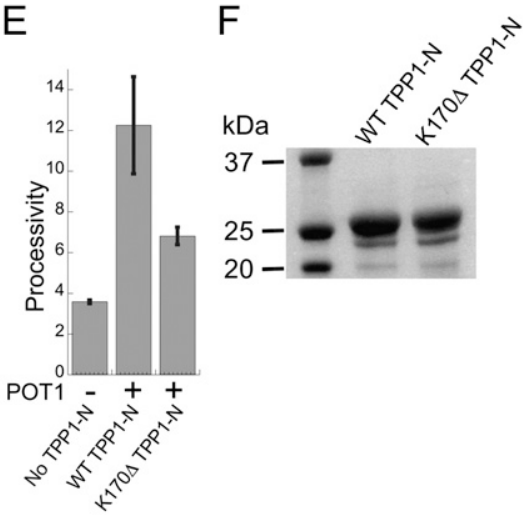

Figure 4. TPP1-K170 $\Delta$ is defective in stimulating telomerase enzymatic processivity. $(A) \mathrm{Di}$ rect telomerase primer extension assays using lysates from HeLa cells cotransfected with a TR, TERT, and POT1 and the indicated TPP1 plasmids. The number of (hexameric) telomeric repeats added by telomerase is indicated at the left. The region of the gel representing bands indicative of high processivity is indicated by a vertical bar at the left. (B) Direct telomerase primer extension assays using lysates from HEK293T cells supplemented with $500 \mathrm{nM}$ POT1 and the indicated TPP1-N proteins (500 $\mathrm{nM}$ each). $(C)$ Quantitation of processivity from three independent sets of experiments of which $A$ is representative; mean values and standard deviations (error bars) were plotted. (D) Immunoblot of lysates used in $A$ probed with anti-Flag antibody-HRP conjugate showing uniform TPP1, TERT, and POT1 protein expression. (E) Quantitation of processivity from three independent sets of experiments of which $B$ is representative. (F) Coomassie-stained SDS-PAGE of $4 \mu \mathrm{g}$ each of the indicated TPP1-N proteins. the amino acid side chain of E169 is withdrawn from the surface and buried in the core of the protein structure (Fig. $6 \mathrm{~B}, \mathrm{C})$. In comparison, a model of the missense mutation K170A does not exhibit any gross conformational changes in E168, E169, or E171 (data not shown), suggesting a structural basis for the modest effect of K170A on telomerase recruitment (Zhong et al. 2012). In summary, our structural modeling suggests that deletion of K170 occludes E169 from telomerase binding and reduces the extent of the acidic patch on TPP1-OB, thereby compromising telomerase recruitment and processivity.

\section{Discussion}

Here we describe an individual affected by the severe DC variant $\mathrm{HH}$ who harbors two $A C D$ mutations affecting two distinct TPP1 domains. TPP1 interacts with both POT1 and TIN2, forming a bridge between the ssDNAbinding and dsDNA-binding components of the shelterin complex, thereby enabling proper chromosome end protection (Palm and de Lange 2008). TPP1 recruits telomerase via its TEL patch, allowing efficient extension of chromosome ends in actively replicating cells. The mutation affecting the TEL patch, K170 $\Delta$, abrogates telomerase recruitment and reduces telomerase enzymatic processivity. The TIN2-binding domain mutation P491T showed a modest reduction in the interaction between TPP1 and TIN2 but did not significantly affect telomerase recruitment or processivity.

To understand the functional significance of the K170 $\Delta$ mutation of TPP1, we performed telomerase recruitment assays using IF/FISH (Fig. 3) and telomerase activity assays (Fig. 4). Our results demonstrated that K170 compromises both telomerase recruitment and processivity. K170 is located adjacent to the TEL patch amino acids E168, E169, and E171, which form an acidic patch on the TPP1-OB structure that is critical for telomerase function. Our structural modeling suggests that deletion of K170 occludes E169 from telomerase binding and reduces the extent of the acidic patch on TPP1-OB, which compromises telomerase recruitment and processivity (Fig. 6). However, in the absence of a crystal structure for K170ه, we cannot rule out additional disruptive changes in the TEL patch caused by deletion of K170.

P491 resides in the TIN2-binding domain of TPP1, which is important for recruiting TPP1 (and hence telomerase) to telomeres but is dispensable for telomerase processivity. As expected, the P491T amino acid change did not result in a significant reduction in telomerase processivity (Supplemental Fig. S2) or interaction with telomerase at telomeres (Fig. 3). However, we observed that P491T marginally inhibited the interaction between TIN2 and TPP1 (Fig. 5A,B). The physiological relevance of this partial TIN2-binding defect is unclear; 
A
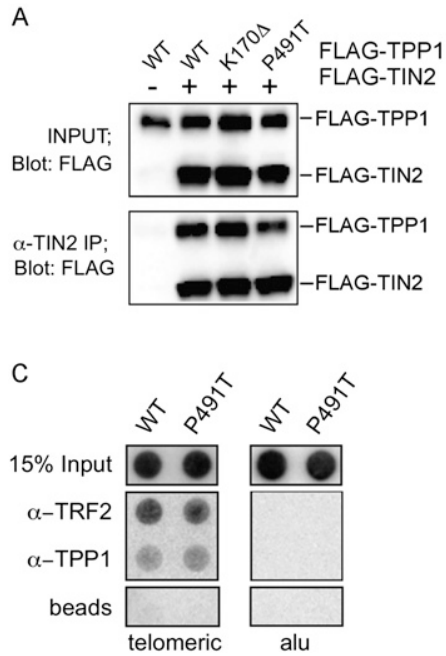

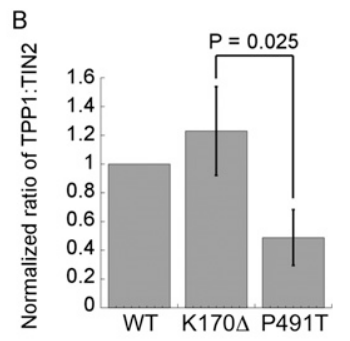

D

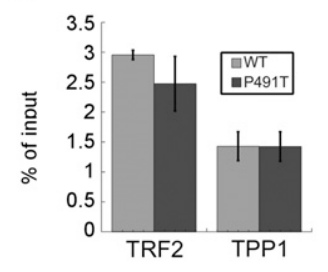

Figure 5. Effect of TPP1 disease mutations on interaction with TIN2 and telomeres. (A) Immunoblot using an HRP-conjugated anti-Flag antibody of lysates from HeLa cells transfected with Flag-TPP1 (indicated construct) and Flag TIN2 either before immunoprecipitation (INPUT) or after immunoprecipitation using an antibody against TIN2 ( $\alpha$-TIN2 IP). (B) The ratio of the Flag signal for TPP1 versus TIN2 normalized against wildtype (WT) TPP1/TIN2 was calculated for four independent experiments, and the mean values and standard deviations (error bars) were plotted. Two-tailed Student $t$-test with respect to K170 $\Delta$ was used to calculate the $P$-value for P491T. $(C)$ Telomere ChIP was conducted with HeLa1.2.11 cells transfected with plasmids encoding either TPP1 (wild type) or TPP1-P491T and immunoprecipitated with antibodies against the indicated proteins. The associated DNA was visualized with Southern blotting using either a ${ }^{32} \mathrm{P}$-labeled telomeric probe or a probe that recognizes Alu repeats. $(D)$ Quantitation of data from two independent experiments of which $C$ is representative. Mean values and standard errors of the mean (error bars) were plotted.

TPP1-P491T is present at telomeres at wild-type levels by ChIP, suggesting that the reduction in TIN2 binding is not sufficient to impact TPP1 recruitment in vivo (Fig. 5C,D). Because our analysis of P491T was done using transient transfections, it is possible that subtle phenotypes were masked via overexpression. Additionally, our analyses assessed the defects of TPP1-K170 and TPP1-P491T individually, while the severely affected proband harbors both variants; it is possible that the combination of these two alleles is more deleterious than the presence of either single allele. Therefore, we cannot exclude the possibility that TPP1-P491T is a disease modifier in the proband, although any potential contribution of P491T to the disease in the proband is likely minor compared with that of the K170 $\Delta$ mutation.

The data indicating that TPP1-K170 $\Delta$ severely compromises telomerase recruitment and processivity while TPP1-P491T has no significant effect on telomerase recruitment are consistent with the phenotypes associated with the family members having one or both of these mutations. The heterozygous carriers of TPP1-K170 $/$ the father and older sister), while clinically healthy at this time, are affected on a molecular level: Their telomeres are below the first percentile for age, an important consideration for family planning and potential bone marrow donation to affected relatives. The mother, a carrier of $\mathrm{P} 491 \mathrm{~T}$, is currently unaffected and has telomeres between the 10th and 50th percentiles, suggesting that $\mathrm{P} 491 \mathrm{~T}$ does not cause a significant change in telomere length; this is consistent with the minimal defects that we observed for this allele. The healthy twins do not harbor either TPP1 mutation, although their telomeres are at the low end of the normal range for their age; this is presumably a consequence of inheritance from at least one parent with very short telomeres (Broer et al. 2013). The proband, the most severely affected individual in this family, is also the only one to harbor both K170 and P491T. The two TPP1 mutations may have a synergistic relationship in which a modest defect with the P491T allele is magnified in an environment where TPP1 is already deficient due to the K170 $\Delta$ mutation. Alternatively, a minimal P491T defect may be sufficient to drop TPP1 function below a certain functional threshold in the context of the K170 mutation, resulting in disease. Characterization of endogenous TPP1 expression and function in cells derived from the proband and his family members will likely provide further insight into the precise contribution of $\mathrm{P} 491 \mathrm{~T}$ to telomere maintenance and $\mathrm{HH}$. We cannot rule out the presence of other diseasemodifying factors, genetic anticipation, or incomplete penetrance in contributing to development of $\mathrm{HH}$ in the proband but not in other K170 $\Delta$ carriers.

TPP1 has previously been implicated in the proper functioning of the tissues most affected by $\mathrm{DC}$ and $\mathrm{HH}$. In mice, the adrenocortical dysplasia (acd) mutant phenotype, caused by a hypomorphic allele of Tpp1, includes a number of features of DC, including growth retardation, skin hyperpigmentation, and sparse hair (Keegan et al. 2005). In addition, mouse hematopoietic stem cells
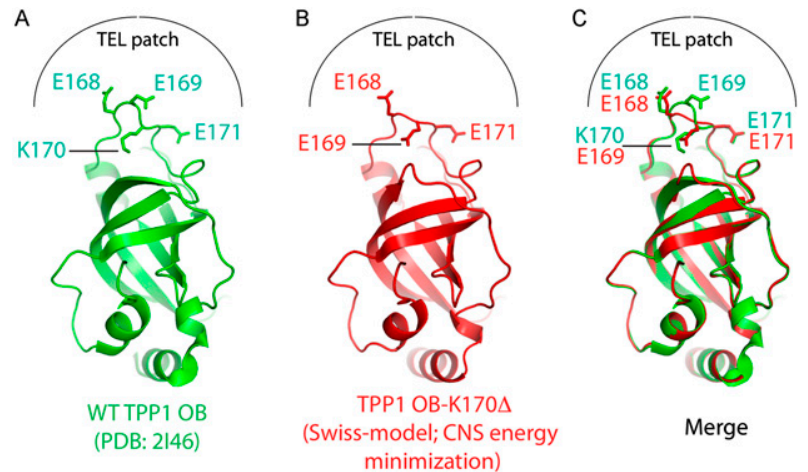

Figure 6. Structural model for K170 $\Delta$ dysfunction. $(A)$ Ribbon view of wild-type (WT) TPP1-OB domain crystal structure (PDB: 2I46), with E168, E169, K170, and E171 side chains shown in stick representations. (B) Ribbon view of structural model of K170 $\Delta$ generated using the wild-type structure as a template. Note how, in the absence of K170 in the model, the E169 side chain flips toward the core of the protein in contrast to its surface-exposed conformation in the wild-type structure. $(C)$ Superposition of the wild-type crystal structure and the model for $\mathrm{K} 170 \Delta$. 
homozygous for the acd allele are profoundly defective in transplantation assays, and complete inactivation of Tpp1 results in severe depletion of hematopoietic progenitors (Jones et al. 2014). Deletion of Tpp1 in the epithelial tissue leads to perinatal death, severe skin hyperpigmentation, defective hair follicle morphogenesis, and epithelial dysplasia (Tejera et al. 2010). While the above studies do not necessarily implicate the TEL patch of TPP1 in stem cell function, a very recent study using genetic engineering of human embryonic stem cells has revealed that deletion of a segment of the TEL patch that includes K170 results in telomere shortening and decreased cell viability (Sexton et al. 2014). These reports and our current study together suggest that reduced telomerase recruitment and processivity caused by perturbation of the TEL patch of TPP1 result in reduced stem cell function, which provides a mechanism explaining the characteristic mucocutaneous and hematopoietic features of DC.

TPP1 is not the first shelterin component implicated in DC; mutations in exon 6a of TINF2 result in DC, $\mathrm{HH}$, and the related telomere biology disorders of aplastic anemia and Revesz syndrome (Savage et al. 2008; Canudas et al. 2011; Yang et al. 2011; Frescas and de Lange 2014). However, TINF2 DC mutations, which do not affect interaction of TIN2 with any of its shelterin-binding partners, cause telomere shortening via mechanisms that involve both telomerase-dependent and telomeraseindependent pathways. In contrast, the deletion in the TEL patch of TPP1 described here provides a more direct model for telomere length shortening resulting from diminished telomerase recruitment to telomeres and reduced telomerase enzymatic processivity. In summary, this is the first report of $\mathrm{DC} / \mathrm{HH}$ caused by germline mutations in TPP1 and further illustrates the importance of this shelterin component in human telomere biology.

\section{Materials and methods}

\section{Patients}

Patient NCI-275-1 and his family were participants in an institutional review board (IRB)-approved longitudinal cohort study at the National Cancer Institute (NCI) entitled "Etiologic Investigation of Cancer Susceptibility in Inherited Bone Marrow Failure Syndromes" (NCI 02-C-0052; http://www.clinicaltrials. gov; identifier: NCT00027274). This study includes comprehensive family history and individual history questionnaires, detailed medical record review, and biospecimen collection (Alter et al. 2010). The proband, his older sister, younger twin sisters, mother, and father were evaluated at the National Institutes of Health (NIH) Clinical Center by the Inherited Bone Marrow Failure Syndromes (IBMFS) study team. Telomere length was evaluated by flow cytometry with FISH in leukocytes (Baerlocher et al. 2006).

\section{Exome sequencing and analysis}

Whole-exome sequencing for family NCI-275 was performed at the NCI Cancer Genomics Research Laboratory as previously described (Ballew et al. 2013) with the following modifications.
Genomic DNA libraries were prepared and amplified with the Bioo Scientific NEXTflex Pre-Capture combo kit (Bioo Scientific) according to the manufacturer's protocol and then cleaned with Agencourt AMPure XP reagent (Beckman Coulter, Inc.) according to the Bioo-provided protocol. Amplified sample libraries were quantified using Quant-iT PicoGreen dsDNA reagent (Life Technologies). Prior to hybridization, four amplified sample libraries with unique index adapters were combined in equal amounts $(275 \mathrm{ng})$ into $1.1-\mu \mathrm{g}$ pools for multiplex sequence capture. Exome sequence capture was performed with NimbleGen's SeqCap EZ Human Exome Library version 3.0, targeting $64 \mathrm{Mb}$ of exonic sequence (Roche NimbleGen, Inc.). Exome-enriched libraries were amplified and purified as above. The resulting post-capture enriched multiplexed sequencing libraries were sequenced as described (Ballew et al. 2013). Approximately $90 \%$ of all targeted bases were covered at a depth of $15 \times$ or greater (Supplemental Table S1).

Sequence reads were trimmed using the Trimmomatic program (Bolger et al. 2014) and then aligned to the hg19 reference genome using Novoalign software version 2.07.14 (http://www. novocraft.com), Picard software version 1.67 (http://picard. sourceforge.net), and the Genome Analysis Toolkit (GATK) (http://www.broadinstitute.org/gatk) (DePristo et al. 2011) as described previously (Ballew et al. 2013). Variant discovery, genotype calling, and annotation were performed as described (Ballew et al. 2013) using data from the University of California at Santa Cruz (UCSC) GoldenPath database (http://hgdownload.cse. ucsc.edu/goldenPath/hg19/database), the ESP6500 data set from the Exome Variant Server, NHLBI ESP (http://evs.gs.washington. edu/EVS; accessed August 2012), the Institute of Systems Biology KAVIAR (known variants) database (http://db.systemsbiology.net/ kaviar; Glusman et al. 2011), the dbSNP (Sherry et al. 2001) build 137 (http://www.ncbi.nlm.nih.gov/projects/SNP), and the 1000 Genomes Project (http://www.1000genomes.org; Abecasis et al. 2010). Variants were also annotated for their presence in an inhouse database consisting of $>1400$ whole exomes that were sequenced in parallel with our DC families. Variants within each family were filtered and categorized as indicated in Supplemental Table S2.

\section{Ion semiconductor sequencing}

Validation of exome sequencing findings in the NCI-275 family was performed by sequencing the entire genomic locus surrounding TPP1 (chr16: 67690393-67695778). A targeted, multiplex PCR primer panel (Supplemental Table S4) was designed using the custom Ion AmpliSeq Designer version 3.0 (Life Technologies). The primer panel covered $95.85 \%$ of the ACD gene, including introns and upstream and downstream sequence. Average amplicon size was $224 \mathrm{bp}$. DNA was amplified using this custom AmpliSeq primer pool, and libraries were prepared following the manufacturer's Ion AmpliSeq library preparation protocol (Life Technologies). Individual samples were barcoded, pooled, templated, and sequenced on the Ion Torrent PGM Sequencer using the Ion PGM Template OT2 200 and Ion PGM Sequencing 200v2 kits per the manufacturer's instructions. Mean read length after sequencing was $140 \mathrm{bp}$.

\section{Sanger sequencing}

EBV-transformed lymphoblastoid cells derived from family members were cultured in IMDM medium containing 20\% FBS and 1\% L-alanyl-L-glutamine. Fibroblast cells derived from the family members were cultured in DMEM containing $10 \%$ FBS. Genomic DNA was isolated from the above cells with 
PUREgene Blood Core Kit B using the manufacturer's instructions (Qiagen). The genomic region of interest was amplified by PCR with sequence-specific primers (Supplemental Table S4). PCR products were sequenced by the University of Michigan DNA Sequencing Core, and the resulting data were analyzed using the Sequencher 5.1 DNA sequence analysis software /Gene Codes Corporation).

\section{In silico analysis}

PolyPhen-2 (http://genetics.bwh.harvard.edu/pph2; Adzhubei et al. 2010), SIFT (http://sift.jcvi.org; Kumar et al. 2009), PROVEAN (http://provean.jcvi.org; Choi et al. 2012), MutationAssessor (http://mutationassessor.org; Reva et al. 2011), MutationTaster (http://mutationtaster.org; Schwarz et al. 2010), FATHMM (http://fathmm.biocompute.org.uk; Shihab et al. 2013), and CADD (Kircher et al. 2014) were used to predict the severity of TPP1 mutations. Multiple sequence alignments were generated for homologous TPP1 protein sequences using COBALT (http:// www.st-va.ncbi.nlm.nih.gov/tools/cobalt; Papadopoulos and Agarwala 2007) and viewed in Jalview (http://www.jalview.org; Waterhouse et al. 2009) to evaluate conservation. Alignments were generated with proteins NP_001075955.1 (Homo sapiens), EPQ14055.1 (Myotis brandtii), AAI49588.1 (Bos taurus), ELR55817.1 (Bos mutus), EHH31762.1 (Macaca mulatta), NP_001032270.1 (Rattus norvegicus), NP_001012656.1 (Mus musculus), EGV97050.1 (Cricetulus griseus), ELV12230.1 (Tupaia chinensis), EHB17028.1 (Heterocephalus glaber), ELK14507.1 (Pteropus alecto), ELK25602.1 (Myotis davidii), EPY84197.1 (Camelus ferus), NP_001089068.1 (Xenopus laevis), and NP_001124265.1 (Danio rerio).

\section{Site-directed mutagenesis}

Oligonucleotides for site-directed mutagenesis were purchased from Integrated DNA Technologies. Indicated variants for expression in cultured human cells were introduced into the $A C D$ gene using fully complementary mutagenic primers (QuickChange site-directed mutagenesis kit, Agilent Technologies). The p3XFlag-TPP1-CMV plasmid was used as the template in the PCR reaction. For engineering TPP1-N constructs containing K170 $\triangle$ for overexpression in bacteria, the pET-Smt3-TPP1-N plasmid (Wang et al. 2007) was used as the template in the PCR (material transfer agreement [MTA] with Cornell University for pSmt3 vector). The $A C D$ gene constructs in the mutant plasmids were sequenced completely to confirm the presence of the intended mutation and exclude the acquisition of unwanted nucleotide changes.

\section{Expression and purification of recombinant proteins}

Purified wild-type and K170 $\Delta$ Smt3-TPP1-N fusion proteins were obtained upon lysis of isopropyl $\beta$-d-thiogalactopyranoside-induced BL21(DE3) cells after nickel-agarose chromatography, treatment with Ulp1 protease (MTA with Cornell University for pUlp1 vector) to cleave the Smt3 tag, and size exclusion chromatography (Superdex 75, GE Life Sciences) as reported previously (Wang et al. 2007). The full-length human POT1 gene was cloned into a His-Sumostar-containing baculoviral expression vector (Life Sensors) and expressed in baculovirus-infected High Five cells (Life Technologies) using vendor recommendations. POT1 protein was purified from these insect cell lysates using nickel-agarose chromatography, treatment with SUMOstar protease (Life Sensors), anion exchange (HiTrap Q HP, GE Life Sciences), and size exclusion chromatography (Superdex 200, GE Life Sciences).

\section{HeLa and HEK293T cell culture}

A clonal HeLa cell line called HeLa-EM2-11ht (Nandakumar et al. 2012) was used for all transient transfection experiments reported here involving HeLa cells. HeLa-EM2-11 ht was obtained from Tet Systems Holdings. KG upon signing an MTA. HeLa1.2.11 cells were used only in the telomere ChIP experiments. Both HeLa cell lines and the HEK293T cells were cultured at $37^{\circ} \mathrm{C}$ in the presence of $5 \% \mathrm{CO}_{2}$; they were propagated in growth medium containing DMEM, 10\% FBS, $1 \mathrm{mM}$ sodium pyruvate, $2 \mathrm{mM}$ L-glutamine, $100 \mathrm{U} / \mathrm{mL}$ penicillin, and $100 \mu \mathrm{g} / \mathrm{mL}$ streptomycin. Doxycycline was added to a final concentration of $200 \mathrm{ng} / \mathrm{mL}$ for expression of the human POT1 (or TIN2) gene that is driven by a tetracycline-inducible promoter from the p3X-Flag-POT1-BI4 (or p3X-Flag-TIN2-BI4) plasmid in HeLa-EM2-11ht cells (Nandakumar et al. 2012).

Culture and manipulation of EBV-transformed lymphoblasts from proband and family members

EBV-transformed lymphoblastoid cells derived from family members were cultured in IMDM medium containing $20 \%$ FBS and $1 \%$ L-alanyl-L-glutamine. They were centrifuged at $1200 \mathrm{rpm}$ for $3 \mathrm{~min}$ and washed with $1 \times$ PBS to pellet the cells. The cells were then resuspended in $1 \%$ BSA-PBS to a final concentration of $\sim 200$ cells per microliter. To prepare slides for FISH analysis, a cytocentrifuge (Rotofix 32A, Hettich Lab Technology) was used. One-hundred microliters of cell suspension was aliquoted into cytocentrifuge funnels and centrifuged at 800 rpm for $3 \mathrm{~min}$. After dissembling the centrifugation setup, a hydrophobic circle was drawn on each slide around the smear using a hydrophobic pen. Cells were fixed with $4 \%$ formaldehyde in PBS for $8 \mathrm{~min}$ and stored at $-20^{\circ} \mathrm{C}$. Slides were thawed to room temperate immediately prior to FISH experiments.

\section{IF/FISH}

IF/FISH experiments to measure telomerase recruitment were performed using published protocols (Nandakumar et al. 2012). Briefly, confluent six-well plates containing HeLa-EM2-11ht cells were transfected with $1 \mu \mathrm{g}$ of p3X-Flag-TPP1-CMV (wildtype or indicated mutant) plasmid (Nakashima et al. 2013), $1 \mu \mathrm{g}$ of TERT-cDNA6/myc-HisC plasmid, and $3 \mu \mathrm{g}$ of phTR-Bluescript II SK|+) plasmid using Lipofectamine 2000 (Life Technologies) following the manufacturer's recommendations. Three days post-transfection, cells were fixed with $4 \%$ formaldehyde in PBS for $8 \mathrm{~min}$. After fixative removal, the cells were permeabilized with PBS containing 0.5\% Triton X-100 (PBS-T), blocked in PBS-T containing nuclease-free $3 \%$ BSA, and incubated with mouse monoclonal anti-Flag M2 (1:500; F1804, Sigma) and rabbit polyclonal anti-coilin (1:100; sc-32860, Santa Cruz Biotechnology ) in PBS-T containing nuclease-free $3 \%$ BSA for $1 \mathrm{~h}$. The cells were then washed in PBS and incubated with Alexa Fluor 488conjugated anti-mouse IgG (Life Technologies) and Alexa Fluor 568-conjugated anti-rabbit IgG (Life Technologies) diluted 1:500 in PBS-T containing nuclease-free $3 \%$ BSA for $30 \mathrm{~min}$ in the dark. The cells were washed in PBS and fixed again in $4 \%$ formaldehyde in PBS for $10 \mathrm{~min}$ at room temperature. The fixative was removed, and the cells were incubated successively in $70 \%$, $95 \%$, and $100 \%$ ethanol. Upon removal of ethanol, cells were rehydrated in $50 \%$ formamide in $2 \times$ SSC buffer for $5 \mathrm{~min}$. The coverslips were prehybridized with solution containing $100 \mathrm{mg} /$ $\mathrm{mL}$ dextran sulfate, $0.125 \mathrm{mg} / \mathrm{mL}$ Escherichia coli tRNA, $0.5 \mathrm{mg} / \mathrm{mL}$ salmon sperm DNA, $1 \mathrm{mg} / \mathrm{mL}$ nuclease-free BSA, $1 \mathrm{mM}$ vanadyl ribonucleoside complexes, and $50 \%$ formamide in $2 \times$ SSC for $1 \mathrm{~h}$ at $37^{\circ} \mathrm{C}$ in a humidified chamber. Prehybridization buffer was then removed, and the coverslips were incubated 
overnight at $37^{\circ} \mathrm{C}$ in a dark humidified chamber in hybridization solution containing a mixture of three Cy5-conjugated TR probes (90 ng of each probe per coverslip) (Abreu et al. 2011). The next morning, the cells were washed with $50 \%$ formamide in $2 \times$ SSC followed by PBS, and the coverslips were mounted on microscope slides using ProLong Gold anti-fade reagent containing DAPI (Life Technologies). The coverslips were sealed using transparent nail polish and stored at $-20^{\circ} \mathrm{C}$. Imaging was performed using a laser-scanning confocal microscope (SP5, Leica) and a $100 \times$ oil objective. Images were processed using Image and Adobe Photoshop. Pseudocolored representative cells are shown in figure panels. Mean and standard deviations of three experiments, each involving 100-150 telomeric foci, were plotted for each TPP1 construct. For IF experiments to detect RAP1, rabbit polyclonal anti-RAP1 (1:500; NB100-292, Novus Biologicals) was used. Telomere FISH of EBV-transformed lymphoblasts was performed with a red fluorescence probe: Cy3-OOCCСТAACCCTAACCCTAA-3' (Bio-Synthesis, Inc.).

\section{Telomerase activity assays}

Both versions of the direct primer extension experiments to measure telomerase processivity shown in Figure 4 were based on published protocols (Nandakumar et al. 2012). Briefly, for the experiments shown in Figure 4, A, C, and D, HeLa-EM2-11ht cells grown in the wells of a six-well plate were transfected with the indicated plasmid DNA using Lipofectamine 2000 (Life Technologies) using the manufacturer's recommendations. One microgram of TERT-cDNA6/myc-HisC, $3 \mu \mathrm{g}$ of phTR-Bluescript II SK $(+), 1.5 \mu \mathrm{g}$ of p3X-Flag-POT1-BI4, and 0.5-0.7 $\mu \mathrm{g}$ of p3X-FlagTPP1-CMV (wild type or mutant) were added per transfection. In control transfections where POT1 and TPP1 were omitted, $2 \mu \mathrm{g}$ of empty vector was included. Two days post-transfection, the cells were trypsinized, washed with PBS, lysed in $100 \mu \mathrm{L}$ of CHAPS lysis buffer (Latrick and Cech 2010), and centrifuged $(13,600 \mathrm{rpm}$ for $10 \mathrm{~min})$ to remove cell debris. The clarified lysates were flash-frozen in liquid nitrogen and stored at $-80^{\circ} \mathrm{C}$. Telomerase reactions were carried out in $20-\mu \mathrm{L}$ volumes containing $50 \mathrm{mM}$ Tris- $\mathrm{Cl}(\mathrm{pH} 8.0), 30 \mathrm{mM} \mathrm{KCl}, 1 \mathrm{mM}$ spermidine, $1 \mathrm{mM} \mathrm{MgCl}, 5 \mathrm{mM} \beta$-mercaptoethanol, $1 \mu \mathrm{M}$ primer a5 (TTAGGGTTAGCGTTAGGG), $500 \mu \mathrm{M}$ dATP, $500 \mu \mathrm{M}$ dTTP, $2.92 \mu \mathrm{M}$ unlabeled dGTP, $0.33 \mu \mathrm{M}$ radiolabeled dGTP $(3000 \mathrm{Ci} /$ $\mathrm{mmol}$ ), and $3 \mu \mathrm{L}$ of HeLa-EM2-11ht cell extracts for $60 \mathrm{~min}$ at $30^{\circ} \mathrm{C}$. Reactions were stopped with buffer containing $100 \mu \mathrm{L}$ of 3.6 M ammonium acetate and $20 \mu \mathrm{g}$ of glycogen and precipitated with ethanol. The pellets were resuspended in $10 \mu \mathrm{L}$ of $\mathrm{H}_{2} \mathrm{O}$ and 10 $\mu \mathrm{L}$ of loading buffer containing $95 \%$ formamide, heated for $10 \mathrm{~min}$ at $95^{\circ} \mathrm{C}$, and resolved on a $10 \%$ acrylamide, $7 \mathrm{M}$ urea, and $1 \times \mathrm{TBE}$ sequencing gel. Gels were dried and imaged on a PhosphorImager (Storm; GE), and the data were analyzed using Imagequant TL (GE Life Sciences) software. Processivity calculations were performed exactly as described previously (Latrick and Cech 2010). Briefly, the intensities of individual bands in the ladder generated by telomerase activity in each lane were quantified and divided by the number of added guanosine nucleotides. For a given band $n$, the fraction left behind (FLB), which is the sum of counts for repeats $(1-n)$ divided by the total counts in the lane, was calculated. Next, $\ln (1-$ FLB $)$ was plotted against repeat number for each lane, and the plot was fit with a linear regression equation with slope $m$. The processivity value, which is plotted in Figure 4, C and E, equals $-0.693 / \mathrm{m}$.

For telomerase activity assays shown in Figure 4, B, E, and F, HEK293T cells were transfected with TERT-cDNA6/myc-HisC and phTR-Bluescript II SK(+) plasmids as described for HeLa, but plasmids encoding POT1 and TPP1 were omitted. Telomerase extracts were prepared exactly as detailed above for HeLa lysates.
The telomerase assay was also performed exactly as above with the exception that purified POT1 and TPP1-N proteins (wild type or K170 ) were preincubated with the DNA primer for $5 \mathrm{~min}$ on ice prior to addition of the telomerase extract. All subsequent steps of the assay, including electrophoresis, gel-drying, imaging, and processivity analyses, were performed exactly as detailed above for telomerase assays with HeLa extracts.

\section{Co-IP assay}

HeLa-EM2-11ht cells were seeded and transfected with $1 \mu$ g each of plasmids encoding Flag-TIN2 and wild-type or mutant FlagTPP1. After $24 \mathrm{~h}$ of transfection, cells were washed with PBS, dislodged with a cell scraper using $400 \mu \mathrm{L}$ of ice-cold lysis buffer (50 mM Tris-Cl at pH 7.4, 20\% glycerol, 1 mM EDTA, $150 \mathrm{mM}$ $\mathrm{NaCl}, 0.5 \%$ Triton X-100, $0.02 \%$ SDS, $1 \mathrm{mM}$ dithiothreitol, $2 \mathrm{mM}$ phenylmethylsulfonyl fluoride, complete protease inhibitor cocktail [Roch]), and kept on ice. After $5 \mathrm{~min}, 20 \mu \mathrm{L}$ of $5 \mathrm{M}$ $\mathrm{NaCl}$ was added and mixed. After another 5 min on ice, $420 \mu \mathrm{L}$ of ice-cold water was added and mixed before immediate centrifugation (13,600 rpm for $10 \mathrm{~min})$. Supernatants were collected and used directly for immunoprecipitation. Lysate $(40 \mu \mathrm{L})$ added to 40 $\mu \mathrm{L}$ of $4 \times$ SDS gel loading buffer was kept aside for analysis of "input" samples. Five microliters of anti-TIN2 antibody was added, followed by incubation overnight at $4{ }^{\circ} \mathrm{C}$. Fifty microliters of protein $\mathrm{A} / \mathrm{G}$ sepharose beads (Pierce; Thermo Scientific) preincubated with $100 \mathrm{mg} / \mathrm{mL}$ BSA in PBS was added, and samples were mixed with rocking on a nutator for $2 \mathrm{~h}$ at $4^{\circ} \mathrm{C}$. Beads were washed three times with 1:1 diluted lysis buffer, and proteins were eluted by adding an equal volume of $2 \times$ SDS gel loading buffer for analysis of "bead" samples. All "input" $(10 \mu \mathrm{L})$ and "bead" $(15 \mu \mathrm{L})$ samples were heated for $12-14 \mathrm{~min}$ at $90^{\circ} \mathrm{C}$ and analyzed by SDS-PAGE and immunoblotting using HRPconjugated anti-Flag antibody. The fraction of TIN2 that is bound by TPP1 (normalized against the ratio of wild-type TPP1:wild-type TIN2) was determined by quantitation of the chemiluminescence signal using a ChemiDoc MP gel imager (Bio-Rad) and subsequent analysis using AlphaView software (ProteinSimple). Results from four independent experiments were used to generate means and standard deviations.

\section{Telomere ChIP}

HeLa1.2.11 cells were transfected with the p3X-Flag-TPP1-CMV (either wild type or P491T) as detailed above for HeLa-EM2-11ht. Transfected cells were processed for ChIP as described previously (Bisht et al. 2012). Following cell lysis, 15\% of the lysates were kept aside to serve as "input" samples. Immunoprecipitation on the remaining $85 \%$ of the lysates was performed by addition of 4 $\mu \mathrm{g}$ of mouse anti-TRF2 4A794.15 (NB100-56506, Novus Biological) and $4 \mu \mathrm{g}$ of monoclonal anti-ACD (H00065057-M02, Abnova) antibodies. Hybridization was performed in Church buffer (0.5 M sodium phosphate buffer at pH 7.2, 1\% BSA, $1 \mathrm{mM}$ EDTA, 7\% SDS) as described previously (de Lange 1992) using ${ }^{32}$ P-labeled (TTAGGG) ${ }_{4}$ or an oligonucleotide probe to detect Alu repeats (Abreu et al. 2010). Following hybridization, membranes were washed to reduce nonspecific binding of the probe, imaged using a PhosphorImager (Storm, GE Life Sciences), and quantified using ImageJ software. The percentage of input DNA that was pulled down was plotted.

\section{Structural modeling}

The Web-based Swiss Model software (http://swissmodel. expasy.org; Arnold et al. 2006) was used to create a homology model for TPP1-OB K170 $\Delta$ based on the crystal structure of 
TPP1-OB wild type (PDB: 2I46). The homology model was subjected to energy minimization using the crystallography and NMR (nuclear magnetic resonance) system (CNS) program (http://cns-online.org/v1.3; Brunger 2007) to furnish the model displayed in Figure 6, B and C.

\section{Acknowledgments}

We thank Valerie Tesmer (J.N. laboratory) for expressing and purifying human POT1 protein from insect cells, Jooho Chung (I.M. laboratory) and Dr. David Ginsburg (University of Michigan) for access to and help with the use of the cytocentrifuge, Gregg Sobocinski (University of Michigan) for help with microscopy, Titia de Lange (Rockefeller University) for the rabbit polyclonal TIN2 and TPP1 antibodies and the HeLa1.2.11 cell line, Joachim Lingner (EPFL, Lausanne, Switzerland) for the TERT-cDNA6/myc-HisC plasmid and phTR-Bluescript II SK(+) plasmids, Tom Cech (University of Colorado) for the p3X-FlagTPP1-CMV plasmid, and Lisa Leathwood, RN, Ann Carr, MS, and Maureen Risch, RN, Westat (Rockville, MD) for their excellent study support. We are grateful to the study participants for their valuable contributions. This work was supported in part by NIH R00-CA-167644-03 (to J.N.), University of Michigan Nathan Shock Center P30-AG-013283 (pilot grant to J.N.), NIH R01-HD-058606 (to C.E.K.), a University of Michigan Rackham Graduate School Barbour Scholarship (to H.K.), the D. Dan and Betty Kahn Foundation (to I.M.), the intramural research program of the Division of Cancer Epidemiology and Genetics, National Cancer Institute, and contract HHSN2612006550018C with Westat.

\section{References}

Abecasis GR, Altshuler D, Auton A, Brooks LD, Durbin RM, Gibbs RA, Hurles ME, McVean GA, Consortium GP. 2010. A map of human genome variation from population-scale sequencing. Nature 467: 1061-1073.

Abreu E, Aritonovska E, Reichenbach P, Cristofari G, Culp B, Terns RM, Lingner J, Terns MP. 2010. TIN2-tethered TPP1 recruits human telomerase to telomeres in vivo. Mol Cell Biol 30: 2971-2982.

Abreu E, Terns RM, Terns MP. 2011. Visualization of human telomerase localization by fluorescence microscopy techniques. Methods Mol Biol 735: 125-137.

Adzhubei IA, Schmidt S, Peshkin L, Ramensky VE, Gerasimova A, Bork P, Kondrashov AS, Sunyaev SR. 2010. A method and server for predicting damaging missense mutations. Nat Methods 7: 248-249.

Alter BP, Giri N, Savage SA, Peters JA, Loud JT, Leathwood L, Carr AG, Greene MH, Rosenberg PS. 2010. Malignancies and survival patterns in the National Cancer Institute Inherited Bone Marrow Failure Syndromes cohort study. Br I Haematol 150: 179-188.

Alter BP, Rosenberg PS, Giri N, Baerlocher GM, Lansdorp PM, Savage SA. 2012. Telomere length is associated with disease severity and declines with age in dyskeratosis congenita. Haematologica 97: 353-359.

Arnold K, Bordoli L, Kopp J, Schwede T. 2006. The SWISSMODEL workspace: a Web-based environment for protein structure homology modelling. Bioinformatics 22: 195201.

Baerlocher GM, Vulto I, de Jong G, Lansdorp PM. 2006. Flow cytometry and FISH to measure the average length of telomeres (flow FISH). Nat Protoc 1: 2365-2376.

Ballew BJ, Savage SA. 2013. Updates on the biology and management of dyskeratosis congenita and related telomere biology disorders. Expert Rev Hematol 6: 327-337.
Ballew BJ, Yeager M, Jacobs K, Giri N, Boland J, Burdett L, Alter BP, Savage SA. 2013. Germline mutations of regulator of telomere elongation helicase 1, RTEL1, in dyskeratosis congenita. Hum Genet 132: 473-480.

Bisht KK, Dudognon C, Chang WG, Sokol ES, Ramirez A, Smith S. 2012. GDP-mannose-4,6-dehydratase is a cytosolic partner of tankyrase 1 that inhibits its poly(ADP-ribose) polymerase activity. Mol Cell Biol 32: 3044-3053.

Bolger AM, Lohse M, Usadel B. 2014. Trimmomatic: a flexible trimmer for Illumina sequence data. Bioinformatics 30: 2114-2120.

Broer L, Codd V, Nyholt DR, Deelen J, Mangino M, Willemsen G, Albrecht E, Amin N, Beekman M, de Geus EJ, et al. 2013. Meta-analysis of telomere length in 19,713 subjects reveals high heritability, stronger maternal inheritance and a paternal age effect. Eur J Hum Genet 21: 1163-1168.

Brunger AT. 2007. Version 1.2 of the crystallography and NMR system. Nat Protoc 2: 2728-2733.

Canudas S, Houghtaling BR, Bhanot M, Sasa G, Savage SA, Bertuch AA, Smith S. 2011. A role for heterochromatin protein $1 \gamma$ at human telomeres. Genes Dev 25: 1807-1819.

Choi Y, Sims GE, Murphy S, Miller JR, Chan AP. 2012. Predicting the functional effect of amino acid substitutions and indels. PLOS ONE 7: e46688.

de Lange T. 1992. Human telomeres are attached to the nuclear matrix. EMBO J 11: 717-724.

DePristo MA, Banks E, Poplin R, Garimella KV, Maguire JR, Hartl C, Philippakis AA, del Angel G, Rivas MA, Hanna M, et al. 2011. A framework for variation discovery and genotyping using next-generation DNA sequencing data. Nat Genet 43: 491-498.

Dokal I. 2011. Dyskeratosis congenita. Hematology Am Soc Hematol Educ Program 2011: 480-486.

Frescas D, de Lange T. 2014. A TIN2 dyskeratosis congenita mutation causes telomerase-independent telomere shortening in mice. Genes Dev 28: 153-166.

Glusman G, Caballero J, Mauldin DE, Hood L, Roach JC. 2011. Kaviar: an accessible system for testing SNV novelty. Bioinformatics 27: 3216-3217.

Houghtaling BR, Cuttonaro L, Chang W, Smith S. 2004. A dynamic molecular link between the telomere length regulator TRF1 and the chromosome end protector TRF2. Curr Biol 14: 1621-1631.

Jones M, Osawa G, Regal JA, Weinberg DN, Taggart J, Kocak H, Friedman A, Ferguson DO, Keegan CE, Maillard I. 2014. Hematopoietic stem cells are acutely sensitive to Acd shelterin gene inactivation. J Clin Invest 124: 353-366.

Jyonouchi S, Forbes L, Ruchelli E, Sullivan KE. 2011. Dyskeratosis congenita: a combined immunodeficiency with broad clinical spectrum-a single-center pediatric experience. Pediatr Allergy Immunol 22: 313-319.

Keegan CE, Hutz JE, Else T, Adamska M, Shah SP, Kent AE, Howes JM, Beamer WG, Hammer GD. 2005. Urogenital and caudal dysgenesis in adrenocortical dysplasia (acd) mice is caused by a splicing mutation in a novel telomeric regulator. Hum Mol Genet 14: 113-123.

Keller RB, Gagne KE, Usmani GN, Asdourian GK, Williams DA, Hofmann I, Agarwal S. 2012. CTC1 Mutations in a patient with dyskeratosis congenita. Pediatr Blood Cancer 59: 311314.

Kircher M, Witten DM, Jain P, O'Roak BJ, Cooper GM, Shendure J. 2014. A general framework for estimating the relative pathogenicity of human genetic variants. Nat Genet 46: 310-315.

Kumar P, Henikoff S, Ng PC. 2009. Predicting the effects of coding non-synonymous variants on protein function using the SIFT algorithm. Nat Protoc 4: 1073-1081. 
Latrick CM, Cech TR. 2010. POT1-TPP1 enhances telomerase processivity by slowing primer dissociation and aiding translocation. EMBO J 29: 924-933.

Le Guen T, Jullien L, Touzot F, Schertzer M, Gaillard L, Perderiset M, Carpentier W, Nitschke P, Picard C, Couillault G, et al. 2013. Human RTEL1 deficiency causes HoyeraalHreidarsson syndrome with short telomeres and genome instability. Hum Mol Genet 22: 3239-3249.

Lei M, Podell ER, Cech TR. 2004. Structure of human POT1 bound to telomeric single-stranded DNA provides a model for chromosome end-protection. Nat Struct Mol Biol 11: 1223-1229.

Liu D, Safari A, O'Connor MS, Chan DW, Laegeler A, Qin J, Songyang Z. 2004. PTOP interacts with POT1 and regulates its localization to telomeres. Nat Cell Biol 6: 673-680.

Nakashima M, Nandakumar J, Sullivan KD, Espinosa JM, Cech TR. 2013. Inhibition of telomerase recruitment and cancer cell death. I Biol Chem 288: 33171-33180.

Nandakumar J, Bell CF, Weidenfeld I, Zaug AJ, Leinwand LA, Cech TR. 2012. The TEL patch of telomere protein TPP1 mediates telomerase recruitment and processivity. Nature 492: 285-289.

Nelson ND, Bertuch AA. 2012. Dyskeratosis congenita as a disorder of telomere maintenance. Mutat Res 730: 43-51.

Palm W, de Lange T. 2008. How shelterin protects mammalian telomeres. Annu Rev Genet 42: 301-334.

Papadopoulos JS, Agarwala R. 2007. COBALT: constraint-based alignment tool for multiple protein sequences. Bioinformatics 23: 1073-1079.

Reva B, Antipin Y, Sander C. 2011. Predicting the functional impact of protein mutations: application to cancer genomics. Nucleic Acids Res 39: e118.

Savage SA, Bertuch AA. 2010. The genetics and clinical manifestations of telomere biology disorders. Genet Med 12: 753764.

Savage SA, Giri N, Baerlocher GM, Orr N, Lansdorp PM, Alter BP. 2008. TINF2, a component of the shelterin telomere protection complex, is mutated in dyskeratosis congenita. Am J Hum Genet 82: 501-509.

Schwarz JM, Rödelsperger C, Schuelke M, Seelow D. 2010. MutationTaster evaluates disease-causing potential of sequence alterations. Nat Methods 7: 575-576.

Sexton AN, Youmans DT, Collins K. 2012. Specificity requirements for human telomere protein interaction with telomerase holoenzyme. I Biol Chem 287: 34455-34464.

Sexton AN, Regalado SG, Lai CS, Cost GJ, O'Neil CM, Urnov FD, Gregory PD, Jaenisch R, Collins K, Hockemeyer D. 2014 Genetic and molecular identification of three human TPP1 functions in telomerase action: recruitment, activation, and homeostasis set point regulation. Genes Dev 28: 1885-1899.

Sherry ST, Ward MH, Kholodov M, Baker J, Phan L, Smigielski EM, Sirotkin K. 2001. dbSNP: the NCBI database of genetic variation. Nucleic Acids Res 29: 308-311.

Shihab HA, Gough J, Cooper DN, Stenson PD, Barker GL, Edwards KJ, Day IN, Gaunt TR. 2013. Predicting the functional, molecular, and phenotypic consequences of amino acid substitutions using hidden Markov models. Hum Mutat 34: 57-65.

Takai KK, Kibe T, Donigian JR, Frescas D, de Lange T. 2011. Telomere protection by TPP1/POT1 requires tethering to TIN2. Mol Cell 44: 647-659.

Tejera AM, Stagno d'Alcontres M, Thanasoula M, Marion RM, Martinez P, Liao C, Flores JM, Tarsounas M, Blasco MA. 2010. TPP1 is required for TERT recruitment, telomere elongation during nuclear reprogramming, and normal skin development in mice. Dev Cell 18: 775-789.
Vulliamy $\mathrm{T}$, Beswick R, Kirwan M, Marrone A, Digweed M, Walne A, Dokal I. 2008. Mutations in the telomerase component NHP2 cause the premature ageing syndrome dyskeratosis congenita. Proc Natl Acad Sci 105: 8073-8078.

Walne AJ, Vulliamy $\mathrm{T}$, Marrone A, Beswick R, Kirwan M, Masunari Y, Al-Qurashi FH, Aljurf M, Dokal I. 2007. Genetic heterogeneity in autosomal recessive dyskeratosis congenita with one subtype due to mutations in the telomeraseassociated protein NOP10. Hum Mol Genet 16: 1619-1629.

Walne AJ, Bhagat T, Kirwan M, Gitiaux C, Desguerre I, Leonard N, Nogales E, Vulliamy T, Dokal IS. 2013a. Mutations in the telomere capping complex in bone marrow failure and related syndromes. Haematologica 98: 334-338.

Walne AJ, Vulliamy T, Kirwan M, Plagnol V, Dokal I. 2013b. Constitutional mutations in RTEL1 cause severe dyskeratosis congenita. Am J Hum Genet 92: 448-453.

Wang F, Podell ER, Zaug AJ, Yang Y, Baciu P, Cech TR, Lei M. 2007. The POT1-TPP1 telomere complex is a telomerase processivity factor. Nature 445: 506-510.

Waterhouse AM, Procter JB, Martin DM, Clamp M, Barton GJ. 2009. Jalview version 2-a multiple sequence alignment editor and analysis workbench. Bioinformatics 25: 1189-1191.

Xin H, Liu D, Wan M, Safari A, Kim H, Sun W, O'Connor MS, Songyang Z. 2007. TPP1 is a homologue of ciliate TEBP- $\beta$ and interacts with POT1 to recruit telomerase. Nature 445: $559-562$.

Yang D, He Q, Kim H, Ma W, Songyang Z. 2011. TIN2 protein dyskeratosis congenita missense mutants are defective in association with telomerase. J Biol Chem 286: 23022-23030.

Ye JZ, Hockemeyer D, Krutchinsky AN, Loayza D, Hooper SM, Chait BT, de Lange T. 2004. POT1-interacting protein PIP1: a telomere length regulator that recruits POT1 to the TIN2/ TRF1 complex. Genes Dev 18: 1649-1654.

Zhong FL, Batista LF, Freund A, Pech MF, Venteicher AS, Artandi SE. 2012. TPP1 OB-fold domain controls telomere maintenance by recruiting telomerase to chromosome ends. Cell 150: 481-494. 


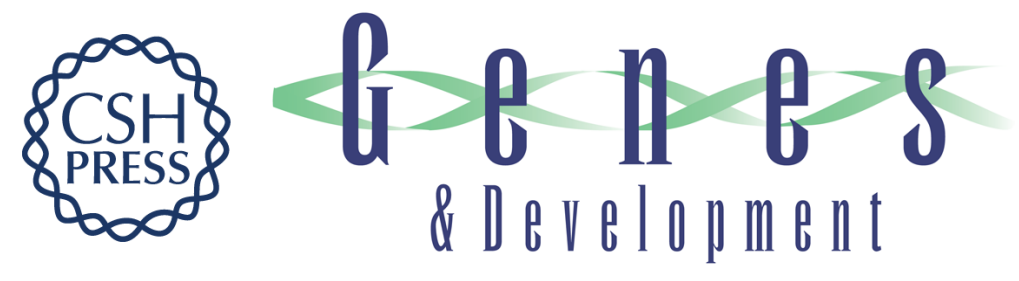

\section{Hoyeraal-Hreidarsson syndrome caused by a germline mutation in the TEL patch of the telomere protein TPP1}

Hande Kocak, Bari J. Ballew, Kamlesh Bisht, et al.

Genes Dev. 2014, 28: originally published online September 18, 2014

Access the most recent version at doi:10.1101/gad.248567.114

\section{Supplemental http://genesdev.cshlp.org/content/suppl/2014/09/17/gad.248567.114.DC1 Material}

References This article cites 57 articles, 14 of which can be accessed free at: http://genesdev.cshlp.org/content/28/19/2090.full.html\#ref-list-1

Creative This article is distributed exclusively by Cold Spring Harbor Laboratory Press for the first Commons six months after the full-issue publication date (see

License http://genesdev.cshlp.org/site/misc/terms.xhtml). After six months, it is available under a Creative Commons License (Attribution-NonCommercial 4.0 International), as described at http://creativecommons.org/licenses/by-nc/4.0/.

Email Alerting Receive free email alerts when new articles cite this article - sign up in the box at the top Service right corner of the article or click here.

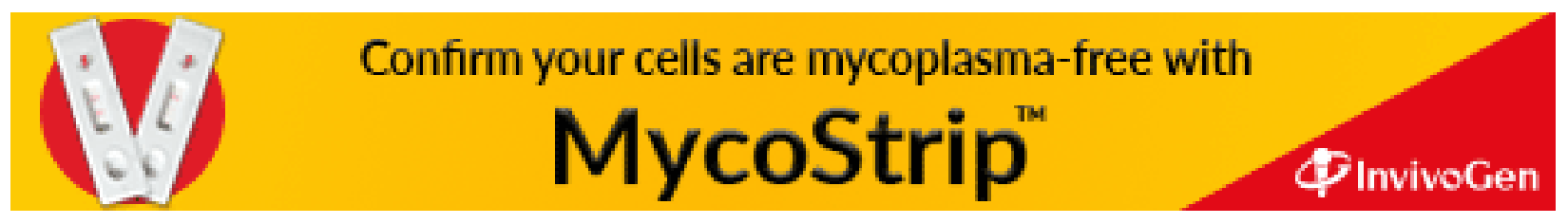

